2019p.

\title{
ЗВАРЮВАМЬНЕ ВИРОБНИЦТВО
}

Посвящается 100-летию со дня рождения профессора Константина Владимировича Багрянского

\author{
(С Лещинский Л.к. ${ }^{1}$, Матвиенко В.Н. ${ }^{2}$, Иванов В.П. ${ }^{3}$, \\ Степнов К.К. ${ }^{4}$, Возьянов Е.И. ${ }^{5}$, Карауланов О.В. ${ }^{6}$
}

\section{ПРОМЫШЛЕННОЕ ОСВОЕНИЕ ТЕХНОЛОГИИ НАПЛАВКИ РОЛИКОВ МНЛЗ}

\begin{abstract}
Установлено, что повысить эффективность прочесса наплавки роликов МНЛЗ в промылиленных условиях позволяет дифференцированный подход к выбору конструкиии поверхностного слоя, материалов, технологии и оборудования для наплавки. Это предусматривает обоснование выбора материалов для наплавки роликов в зависимости от места расположения в зоне вторичного охлаждения, интенсивности износа и растрескивания. Показано, что повысить сопротивление растрескиванию роликов, не изменяя состава наплавленного слоя, позволяют разрывы его сплошности за счёт формирования из одиночных валиков без перекрытия. Предложены и освоены в промышленных условиях схемы наплавки роликов МНЛЗ, предусматривающие дифференцированный подход к выбору ширины валиков, зазора между ними, угла наклона валика в одну или в разные стороны от середины бочки к краям. Для реализачии предложенных схем разработана функциональная система управления наплавочной установкой.

Ключевые слова: ролики машин непрерывного литья заготовок, наплавка, эффективность, дифференцированный подход, выбор материалов и технологии, функииональная схема управления.
\end{abstract}

Лещинській Л.К., Матвієнко В.М., Іванов В.П., Степнов К.К., Возьянов Е.І., Карауланов О.В. Освоєння технології наплавлення роликів МБЛЗ в промислових умовах. Встановлено, що підвищити ефективність процесу наплавлення роликів МБЛЗ в промислових умовах дозволяє диференщійований підхід до вибору конструкиії поверхневого шару, матеріалів, технологї та обладнання для наплавлення. Це передбачає вибір матеріалів для наплавлення роликів в залежності від місия розташування в зоні вторинного охолодження, інтенсивності зносу і розтріскування. Показано, що підвищити опір розтріскуванню роликів, не змінюючи складу наплавленого шару, дозволяють розриви його суиільності за рахунок формування з одиночних валиків без перекриття. При розробиі технології наплавлення слід враховувати, щуо оптимальне співвідношення ширини наплавленого валика і діаметра ролика залежить від кута нахилу валика до твірної циліндра. Виявлено рекомендовані межі зміни кута нахилу валика і встановлено, що для кожного значення кута нахилу існує певне відномення його ширини до діаметру ролика, яке залежить від діаметра. Встановлено розміри зони нагріву основного металу, які визначають необ-

\footnotetext{
${ }^{1}$ д-р техн. наук, профессор, Бостон, США

${ }^{2}$ д-р техн. наук, профессор, ГВУЗ «Приазовский государственньй технический университет», г. Мариуполь, matviyenkovn@gmail.com

3 канд. техн. наук, дочент, ГВУЗ «Приазовский государственный технический университет», г. Мариуполь

${ }_{5}^{4}$ инженер, ГВУЗ «Приазовский государственный технический университет», г. Мариуполь

5 главный сварщикк, ЧАО «МК «Азовсталь»

${ }^{6}$ главный сварщчик, ООО «МЕТИНВЕСТ-МРМЗ»
} 
хідні співвідношення величини зазору між суміжними валиками. Запропоновано $i$ освоєно в промислових умовах схеми наплавлення роликів МБЛЗ, щңо передбачають диферениійований підхід до вибору ширини валиків, зазору між ними, кута нахилу валика в одну або в різні сторони від середини бочки до ї̈ країв. Для реалізації запропонованих схем розроблена функиіональна система управління наплавочною установкою, яка забезпечує узгодження швидкості обертання виробу і переміщення наплавочного апарату. Оснащення системи управління кінцевими вимикачами дозволяє здійснити відробіток траєкторії наплавлення валиків з зазором між ними під заданим кутом до твірної.

Ключові слова: ролики машин безперервного лиття заготовок, наплавлення, диференційований підхід, вибір матеріалів і технології, функціональна схема управління.

L.K. Leshchinskiy, V.N. Matvienko, V.P. Ivanov, K.K. Stepnov, E.I. Vozyanov, O.V. Karaulanov. Industrial mastering the technology of surfacing of continuous casting machine rolls. It has been established that differentiated approach to the choice of surface layer design, materials, technology, and equipment for surfacing makes it possible to increase the efficiency of the continuous casting machine rolls (CCMR) reconditioning. This involves the selection of the materials for surfacing of the rolls depending on their position in the secondary cooling zone, the intensity of wear, and thermomechanical fatigue cracking of surface layer. It has been shown that the breaks in the continuity of the surface layer formed from separated weld beads with gaps between adjacent welds results in the increase of the cracking resistance of the rolls without changing the chemical composition of the surface layer. Developing the continuous casting machine rolls surfacing technology, one should take into account that the optimum ratio of weld bead width to the diameter of the roll depends on the angle of inclination of the weld bead to the generatrix of the cylinder. The recommended limits of the angle of inclination changes have been identified and it has been shown that for each value of the angle there is a certain ratio of the weld bead width to the diameter of the roll; the ratio being independent of the diameter. The schemes of surfacing of the continuous casting machine rolls proposed and mastered in industrial conditions provide a differentiated approach to the choice of the weld bead width, the gap between them, and the angle of bead inclination in multiple directions from the middle of the barrel to the edges. To implement the proposed schemes of surfacing, a functional control system of surfacing installation has been developed. Fitting the control system with limit switches provides the given angle of the weld deposition pass to the generatrix.

Keywords: continuous casting machine rolls, schemes of surfacing, differentiated approach, selection of material and technology, functional control system.

Постановка проблемы. От ресурса роликов машин непрерывного литья заготовок (МНЛЗ) во многом зависит работоспособность МНЛЗ, их внеплановые остановки для замены роликов. Значительные затраты на приобретение и восстановление вызваны большим количеством роликов, эксплуатирующихся на МНЛЗ. С практически непрерывным процессом ремонта путём проточки и наплавки связана необходимость обеспечить высокую эффективность процесса промышленного восстановления роликов МНЛЗ.

Анализ последних исследований и публикаций. Эффективность применения наплавки роликов МНЛЗ зависит от возможности обеспечить снижение числа замен роликовых секций в процессе эксплуатации, уменьшить прямые расходы на такие замены, сократить время простоя машины. Поэтому для разработки технологии наплавки необходимо выбрать оптимальную конструкцию наплавленного слоя, наплавочные материалы, оборудование и средства управления, позволяющие реализовать предложенную технологию. При этом целесообразно использовать дифференцированный подход, учитывающий, что скорость износа приводных роликов в $2,5 \ldots 3,0$ раза выше, чем холостых; быстрее изнашиваются ролики, расположенные в зоне изгиба и разгиба заготовки, а также на входе и выходе в каждой роликовой секции разливочного ручья $[1,2]$.

Исходя из отмеченных условий, важную роль в выборе пути промышленного освоения технологии наплавки роликов МНЛЗ играет оценка и сравнение возможностей реализации это- 
2019p.

p-ISSN: 2225-6733; e-ISSN: 2519-271X

го пути с учётом экономической целесообразности. Этого нельзя не учитывать в связи с тем, что с большим расходом роликов (их парк составляет сотни штук на разливочную машину) связан практически непрерывный процесс их восстановления (упрочнения) наплавкой (рис. 1). По аналогии с градацией материалов, применяемых в промышленном производстве химических веществ, в работе [3] сделана попытка разделения материалов для наплавки роликов МНЛЗ на оригинальные и альтернативные. Такое разделение электродных материалов, обеспечивающих получение наплавленного коррозионностойкого слоя типа X13, связано не только с различием в составе и свойствах, влияющих на ресурс наплавленных роликов, но также со значительной разницей в их стоимости.

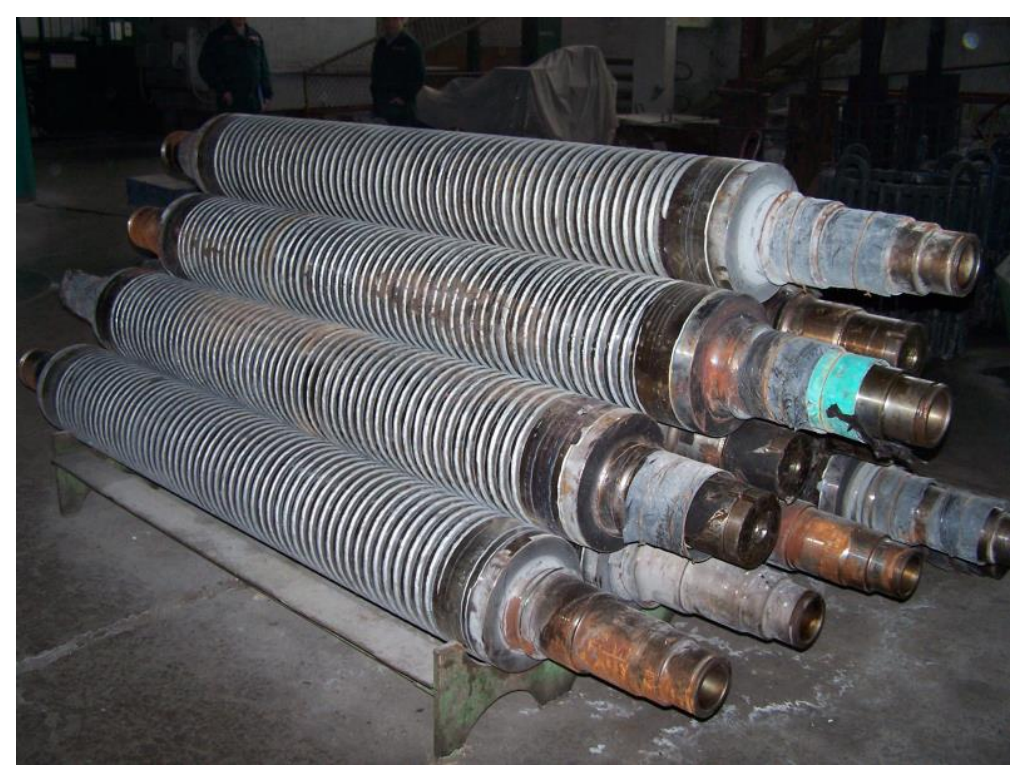

Рис. 1 - Наплавленные ролики МНЛЗ на участке ремонтно-механического завода ООО «МЕТИНВЕСТ-МРМЗ»

Цель статьи - анализ путей повышения эффективности процесса наплавки роликов МНЛЗ при освоении в промышленных условиях.

Изложение основного материала. В зависимости от конкретных условий эксплуатации роликов можно обосновать дифференцированный подход к выбору оригинального или альтернативного состава материала. При восстановлении роликов машин непрерывного литья заготовок предусматривается нанесение подслоя и трёх рабочих слоёв [4]. Для наплавки подслоя низколегированным составом металла 07X1Н1Г1MC используется порошковая проволока 3Ni2.5CrMo (DIN EN14295-2003). При восстановлении бочки приводных роликов (исключая краевые участки) наплавка рабочего слоя 04Х13Н3М1Г1ФАБ обеспечивается порошковой проволокой SK 742-SK (DIN EN8555) диаметром 3,2 мм в сочетании с агломерированным флюсом Record SK (DIN EN760). Режим наплавки: $\mathrm{I}_{\mathrm{H}}=300 \ldots 350 \mathrm{~A}, \mathrm{U}=28 \ldots 32 \mathrm{~B}, \mathrm{v}_{\mathrm{H}}=30$ м/ч. Мартенситная структура ( $10 \%$ феррита) металла характеризуется твёрдостью $42 \ldots 44$ HRC в состоянии наплавки. В отличие от этого для наплавки составом $15 \mathrm{X} 13 \mathrm{H} 2 Г$ ФБ бочки холостых роликов, а также краевых участков бочки приводных роликов, используется порошковая проволока ВЕЛТЕК-Н470 (ТУ У 28.7-31749248-006) диаметром 3,6 мм в сочетании с агломерированным флюсом UFM-4.5.3 (ТУ У 20.5-30816276-002:2012). Это позволяет экономить при восстановлении роликов более $30 \%$ расходов. Здесь следует также отметить данные работы [5], где подтверждается справедливость дифференцированного подхода при выборе наплавочного материала как с учётом условий работы роликов (в частности, агрессивности шлакового гарнисажа), значительно отличающихся для разных МНЛЗ, так и особенностей сквозного производственного цикла эксплуатации и ремонта роликов [6]. Это позволило для повышения ресурса роликов использовать наплавочные материалы с меньшей стоимостью, однако, отличающиеся низкой коррозионной стойкостью, например, состав типа Х5МФ в отличие от широко применяемых составов типа X13...X17. 

2019p.

Дифференцированный подход, по нашему мнению, может использоваться не только при выборе наплавочных материалов, но также к технологии и оборудованию для упрочнения роликов МНЛЗ. Так, технология наплавки сплошным слоем или с разрывами сплошности (с зазором между валиками) может применяться в зависимости от места расположения роликов в зоне вторичного охлаждения на криволинейном, радиальном или горизонтальном участке МНЛЗ. Если для роликов горизонтального участка технология наплавки сплошным слоем может быть предпочтительной, то для роликов криволинейного и радиального участков, где выше уровень термических напряжений, целесообразно формирование наплавленного слоя без перекрытия смежных валиков. Более того, такой подход к выбору технологии наплавки целесообразен в пределах каждого участка МНЛЗ. Для этого необходимы разработка и освоение автоматизированной системы управления маршрутной картой сквозного производственного цикла эксплуатации и восстановления роликов на всех стадиях от приобретения до списания.

$\mathrm{C}$ целью предотвращения образования зон перекрытия смежных валиков, которые характеризуются пониженной твёрдостью и высокой отпускной хрупкостью, что приводит к низкой трещиностойкости этих зон (рис. 2), наплавленный слой формируется с разрывами сплошности (зазорами) (рис. 3), располагающимися на границах смежных валиков [7].

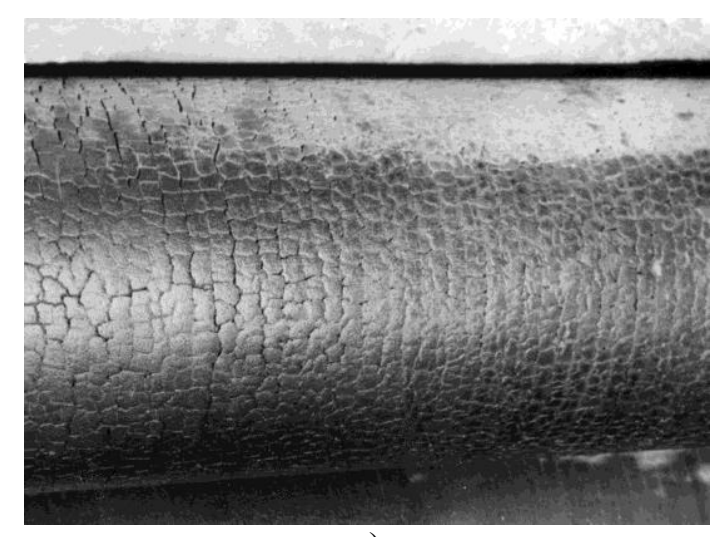

a)

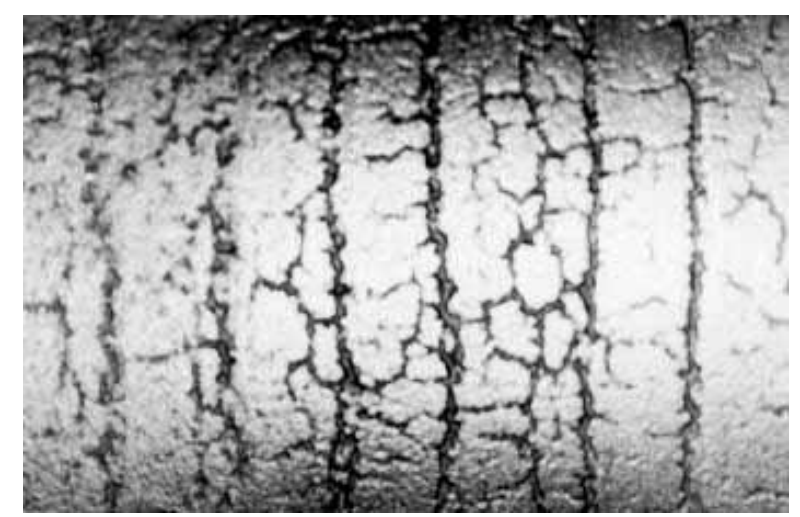

б)

Рис. 2 - Растрескивание поверхности роликов, наплавленных сплошным слоем: a - общий вид рабочей поверхности ролика, б - фрагмент поверхности с трещинами разгара (увеличено)

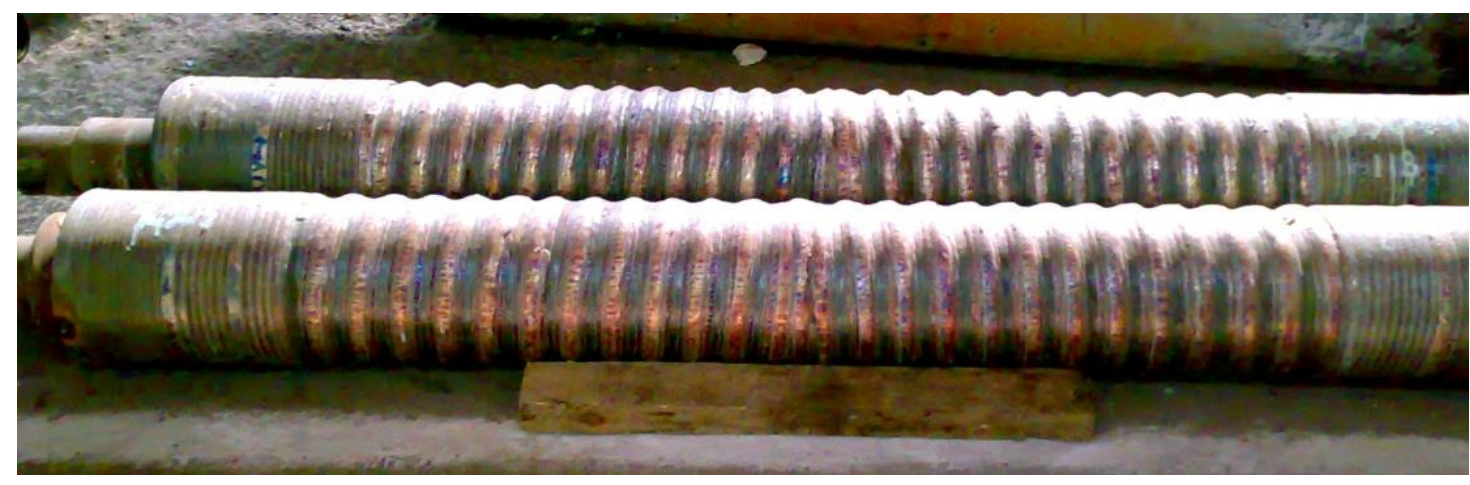

Рис. 3 - Внешний вид роликов, наплавленных с зазором между смежными валиками с наклоном в разные стороны от середины к краям

Кроме того, при разрывах сплошности в меньшей мере перегревается поверхность ролика, контактирующая с литой заготовкой, тем более при уменьшении скорости разливки. За счёт разгружающего влияния разрывов сплошности в слое замкнутого контура снижается уровень остаточных напряжений, что по результатам исследований в работе [8] составляет $20 \ldots 40 \%$. Со снижением уровня напряжений уменьшается не только склонность к зарождению трещин в наплавленном слое, но в большей мере растёт сопротивление её распространению за счёт тор- 
можения зазором. Для этого необходимо ограничить ширину валика, чтобы зависящая от угла наклона к образующей проекция ширины валика на диаметральную плоскость была меньше критической длины трещины. С этой целью ширина валика, отнесенная к диаметру ролика, выбирается в зависимости от угла наклона валика к образующей $\alpha$ (положения вектора скорости наплавки). От этого зависят условия формообразования сварочной ванны на поверхности цилиндра с радиусом, равным радиусу ролика. В зависимости от угла $\alpha$ изменяется соотношение сил, действующих на расплавленный металл ванны, - силы поверхностного натяжения и составляющих силы тяжести (одна из них направлена в сторону, противоположную вектору скорости наплавки, другая - перпендикулярно этому вектору). Кроме того, изменяется влияние критической массы сварочной ванны, с превышением которой сила поверхностного натяжения не может удержать расплавленный металл от растекания, что приводит к нарушению формирования валика. По данным лабораторных испытаний, как и промышленного освоения, при наплавке роликов диаметром 270...380 мм ухудшение формирования, вызванное большой массой ванны, особенно характерно, когда угол наклона становится менее $48 . .50^{\circ}$. Нарушается симметричность поперечного сечения: с одной стороны валика образуется наплыв, с другой сечение ослаблено и образуется подрез.

Поскольку при наплавке роликов глубина проплавления основного металла и высота наплавленного слоя строго ограничены, основным размером, позволяющим уменьшить массу ванны, является её ширина, зависящая от угла $\alpha$. При этом условием обеспечения необходимого качества формирования является ограничение допустимой ширины валика вдоль образующей. Кроме того, дополнительные ограничения ширины связаны с ухудшением условий формирования валика по мере уменьшения диаметра ролика от 380 до 270 мм. Из этого следует, что допустимая ширина валика вдоль образующей зависит также от диаметра ролика. При этом отношение допустимой ширины валика вдоль образующей к диаметру ролика зависит только от угла наклона валика (таблица) и не зависит от диаметра ролика.

Таблица

Отношение допустимой ширины валика вдоль образующей к диаметру ролика в зависимости от угла наклона валика к образующей

\begin{tabular}{|l|c|c|c|c|c|c|}
\hline Угол наклона валика к образующей, град. & 50 & 55 & 60 & 65 & 70 & 75 \\
\hline Отношение ширины валика к диаметру ролика & 0,180 & 0,155 & 0,125 & 0,100 & 0,080 & 0,055 \\
\hline
\end{tabular}

Ограничение ширины валика вдоль образующей должно обеспечить не только требуемое качество формирования, но также ограничить размеры трещины, распространяющейся в диаметральной плоскости (кольцевой трещины). Для роликов зоны вторичного охлаждения МНЛЗ в процессе устойчивого роста поверхностной усталостной трещины в глубину материала (при скорости роста $3,5 \cdot 10^{-4}$ мм/цикл) трещина принимает форму полуэллипса с отношением полудлины к глубине, близком к 0,5. Форма трещины практически неизменна до глубины проникновения в тело ролика, превышающей критическую, при которой может произойти разрушение. Согласно расчётным данным и опыту эксплуатации роликов диаметром $270 \ldots 380$ мм зоны вторичного охлаждения МНЛЗ, критическая глубина поверхностной трещины не должна превышать $0,057 \ldots 0,058$ диаметра. С учётом указанного выше соотношения длины и глубины трещины можно получить, что критическая длина трещины ограничена величиной $0,225 \ldots 0,235$ диаметра ролика. Из соотношения полудлины и глубины трещины следует, что длина трещины, пересекающей наплавленный одиночный валик в диаметральной плоскости, определяется шириной валика и углом наклона к образующей. Допустимую ширину валика, при которой длина поверхностной трещины не больше критической, можно найти из выражения:

$$
b \leq K \cdot D / \operatorname{tg} \alpha,
$$

где $b$ - ширина одиночного валика вдоль образующей; $D$ - диаметр ролика; $\operatorname{tg} \alpha$ - тангенс угла наклона валика к образующей; $K=0,2246$ - эмпирическая постоянная.

Переходя к отношению допустимой ширины валика вдоль образующей к диаметру ролика, получаем $b / D \leq K / \operatorname{tg} \alpha$. С увеличением угла наклона к образующей выше $50^{\circ}$ улучшаются условия формирования валика, поэтому допустимая ширина одиночного валика, наплавляемого за один проход, ограничена не условиями формообразования сварочной ванны, а критической длиной поверхностной трещины, пересекающей валик в диаметральной плоскости. Когда угол 
наклона превышает $75 \ldots 77^{\circ}$, длина трещины не достигает критического значения лишь в случае, если ширина валика вдоль образующей уменьшается до величины технологически трудно достижимой. Такое значение угла $\alpha$ можно рассматривать в качестве верхней границы угла наклона валика к образующей. Обосновав нижнюю и верхнюю границу угла наклона $\alpha$ и установив, что каждому значению угла наклона соответствует определённое отношение допустимой ширины валика вдоль образующей к диаметру ролика, можно определить пределы изменения отношения $b / D$. Как следует из таблицы, эти пределы составляют $0,055 \leq b / D \leq 0,18$.

Необходимая величина зазора между смежными валиками должна быть больше ширины двух зон термического влияния, образующихся в процессе дуговой наплавки под воздействием источника тепла, расположенного на краю зоны нагрева. Исследованиями установлено, что нагрев основного металла в этой зоне описывается в теории распространения тепла при сварке действием точечного источника, а размеры зоны нагрева на краю оцениваются, как $\sim 1 / 6$ общей ширины. Ширина двух этих зон составляет $\sim 1 / 3$ ширины наплавляемого валика. С учётом диапазона допустимой ширины валика при изменении диаметра ролика от 270 до 400 мм, ширина зазора вдоль образующей между смежными валиками составляет $(0,15 \ldots 0,20) \cdot b \leq \Delta \leq(0,32 \ldots 0,35) \cdot b$.

Одним из путей улучшения функциональных характеристик различных типов установок для наплавки роликов МНЛЗ является их модернизация [9]. В то же время, при наплавке роликов МНЛЗ слоем, формируемым из одиночных валиков с зазором, расположенных под углом к образующей, важнейшей задачей является разработка и совершенствование системы управления. В отсутствии согласования скорости вращения изделия и перемещения наплавочного аппарата с применением «ручного» управления устанавливается режим наплавки, размеры валиков и зазор между ними. Однако значительно труднее обеспечить требуемый угол наклона валика к образующей (как правило, используются значения угла наклона, достигающие почти $80^{\circ}$ ). Кроме того, могут возникнуть сложности при реверсе направления движения наплавочного аппарата на краях бочки. Вместе с тем, наплавочные установки с системой управления такого типа успешно эксплуатируются на металлургических комбинатах. В отличие от этого, реализация в полном объёме технологии наплавки слоя, формируемого из расположенных под заданным углом к образующей одиночных валиков с зазором, предусматривает согласование скорости вращения изделия и перемещения наплавочного аппарата. Система управления наплавочным аппаратом с помощью блока слежения (рис. 4) корректирует движение головки в зависимости от сигналов датчиков перемещения (ДП), связанных с электроприводами. При наличии концевых выключателей в местах реверса обеспечивается автоматическая отработка траектории наплавки валиков под заданным углом к образующей с зазором между смежными валиками.

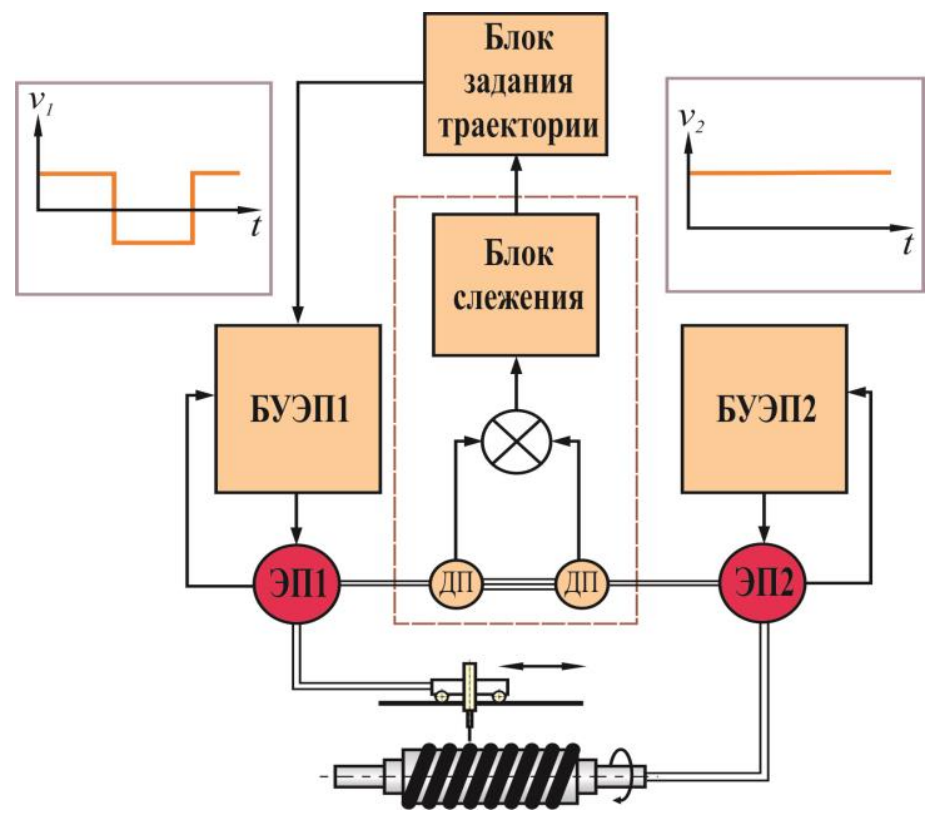

Рис. 4 - Система управления установкой для наплавки роликов МНЛЗ 


\section{Выводы}

1. Повысить эффективность процесса восстановления (упрочнения) роликов МНЛЗ наплавкой в условиях промышленного производства позволяет использование дифференцированного подхода к выбору наплавочных материалов, технологии и оборудования в соответствии с конкретными условиями эксплуатации роликов. Это тем более важно, учитывая объём расходуемых материалов для непрерывного процесса наплавки роликов.

2. Для повышения сопротивления наплавленного слоя поверхностному растрескиванию целесообразно использовать полученные эмпирические соотношения ширины валика и диаметра ролика в зависимости от угла наклона валика к образующей.

3. При освоении разработанной технологии наплавки с формированием поверхностного слоя из одинарных валиков без перекрытия, ресурс роликов зависит от возможности обеспечить соответствие характеристик геометрии валиков, наплавленных в условиях производства, рекомендациям, полученным в результате исследований.

\section{Список использованных источников:}

1. Le Jeune D. Roll Performance in the Hot Strip Mill using Proven Welding Technology and Specially Developed Welding Materials to Reduce Operational Cost and Maximise Productivity / D. Le Jeune, J. Morris, P. Collins // AISTech. 2007 Proceedings. - Vol. I. - Pp. 1-9.

2. Le Jeune D. Roll Welding in the Hot Strip Mill: Pinch Roll Welding / D. Le Jeune, S. Hunt, J. Mathew // Symposium on Welding in Steel Plant and Mining Industry (27-28 February 2006). Pp. 1-5.

3. Le Jeune D. The Weld Cladding of Foot and Top Segment Rolls to Improve Roll Life / D. Le Jeune, J. Morris, P. Collins // AISTech. 2008 Proceedings. - Vol. II. - Pp. 1195-2002.

4. Технологическая инструкция ТИ-413-17-34:2014 «Ремонт роликов МНЛЗ-1, 2 ЧАО «ММК им. Ильича». - ООО «Метинвест-МРМЗ», 2014. - 18 с.

5. Вдовин К.Н. Способы повышения стойкости роликов МНЛЗ / К.Н. Вдовин, А.А. Подосян, А.С. Бердников // Сталь. - 2010. - № 5. - С. 112-114.

6. Improvement in operating efficiency of continuous casting machine slab rolls / E.I. Vozyanov, O.V. Korobka, O.V. Karaulanov, L.K. Leshchinskii, V.N. Matvienko // Metallurgist. - 2018. Vol. 62 (7-8). - Pp. 681-685. - Mode of access: DOI: 10.1007/s11015-018-0708-9.

7. Домбровский Ф.С. Работоспособность наплавленных роликов машин непрерывного литья заготовок / Ф.С. Домбровский, Л.К. Лещинский. - Киев : Институт электросварки им. Е.О. Патона, 1995. - 198 с.

8. Буланов С.Н. Машины непрерывного литья заготовок. Теория и расчёт / С.Н. Буланов, Л.Г. Корзун, Е.П. Парфёнов - Екатеринбург : Уралмаш-Металлургическое оборудование, 2004. - 349 c.

9. Крылов С.В. Модернизация наплавочных установок в условиях ремонтных предприятий / С.В. Крылов, О.В. Карауланов, А.В. Щебетовский // Оборудование и инструмент для профессионалов. - 2018. - № 1. - С. 72-73.

\section{References:}

1. Le Jeune D., Morris J., Collins P. Roll Performance in the Hot Strip Mill using Proven Welding Technology and Specially Developed Welding Materials to Reduce Operational Cost and Maximise Productivity. AISTech. 2007 Proceedings, vol. I, pp. 1-9.

2. Le Jeune D., Hunt S., Mathew J. Roll Welding in the Hot Strip Mill: Pinch Roll Welding. Symposium on Welding in Steel Plant and Mining Industry, 2006, pp. 1-5.

3. Le Jeune D., Morris J., Collins P. The Weld Cladding of Foot and Top Segment Rolls to Improve Roll Life. AISTech. 2008 Proceedings, vol. II, pp. 1195-2002.

4. Technologicheskaya instuktsiya TI-413-17-34:2014 «Remont rolikov MNLZ-1,2 ChAO «MMK im. Illicha» [Technological instruction TI-413-17-34:2014 «Repair of rollers of continuous casting machine-1,2 PJSC «Ilyich Iron and Steel Works» of Mariupol»]. Mariupol, LTD «METINVEST-MRMZ» Publ., 2014. 18 p. (Rus.)

5. Vdovin K.N., Podosyan A.A., Berdnikov A.S. Sposoby povysheniya stoykosti rolikov MNLZ [Ways resistance rollers CASTERS]. Stal - Steel, 2010, no. 5, pp. 112-114. (Rus.)

6. Vozyanov E.I., Korobka O.V., Karaulanov O.V., Leshchinskii L.K., Matvienko V.N. Improve- 
ment in operating efficiency of continuous casting machine slab rolls. Metallurgist, 2018, vol. 62, pp. 681-685. doi:10.1007/s11015-018-0708-9.

7. Dombrovskiy F.S., Leshchinskiy L.K. Rabotosposobnost naplavlennykh rolikov mashin nepreryvnogo litya zagotovok [Operability overlaid rollers continuous casting machines]. Kiev, Institute elektrosvarki im. E.O.Patona Publ., 1995. 198 p. (Rus.)

8. Bulanov S.V., Korzun L.G., Parfenov E.P. Mashiny nepreryvnogo litya zagotovok. Teoriya $i$ raschet [Continuous Billet Casting Machine. Theory and Design]. Ekaterinburg, Uralmach, Metallurgicheskoe oborudovanie Publ., 2004. 349 p. (Rus.)

9. Krylov S.V., Karaulanov O.V., Shchebetovskiy O.V. Modernizatsiya naplavochnykh ustanovok v usloviyakh remontnykh predpriyatiy [Modernization of surfacing installations in the conditions of repair enterprises]. Oborudovanie i instrument dlya professionalov - Equipment and Tools for Professionals, 2018, no. 1, pp. 72-73. (Rus.)

Рецензент: В.И. Щетинина

д-р техн. наук, проф., ГВУЗ «ПГТУ»

Статья поступила 15.03.2019

УДК 621.791.927

doi: 10.31498/2225-6733.38.2019.181370

(C Гулаков С.В. ${ }^{1}$, Бурлака В.В. ${ }^{2}$, Міроненко А.І. ${ }^{3}$, Псарьова I.C. ${ }^{4}$, Тимошенко М.B. ${ }^{5}$

\title{
ДУГОВЕ НАПЛАВЛЕННЯ СТРІЧКОВИМ ЕЛЕКТРОДОМ 3 МАГНІТНИМ КЕРУВАННЯМ
}

\begin{abstract}
Розглянуто можливість регламентованого керування процесом переміщення дуги по торияю стрічкового електрода за рахунок ї̈ взаємодії з наведеним магнітним полем. Запропоновано два шляхи керування прочесом наплавлення - із застосуванням профільованої електродної стрічки і плоскої (непрофільованої). Показано можливість управління закономірністю процесу переміщення дуги по торцю електрода в залежності від умов тепловкладення енергї дуги в електрод і основний метал та зварювальну ванну. Наведено схеми процесу магнітного управління переміщенням дуги по ториюю стрічкового електрода за рахунок дї магнітного поля.

Ключові слова: електродугове наплавлення, перетворювач, стрічковий електрод, якість наплавлення, зварювальна дуга.

Гулаков С.В., Бурлака В.В., Мироненко А.И., Псарева И.С., Тимошенко М.В. Дуговая наплавка ленточным электродом с магнитным управлением. Рассмотрена возможность регламентированного управления процессом перемещения дуги по ториу ленточного электрода за счет ее взаимодействия с наведенным магнитным полем. Предложень два пути управления процессом наплавки - с применением профилированной электродной ленты и плоской (непрофилированной). Показана воз-
\end{abstract}

\footnotetext{
${ }^{1}$ д-р техн. наук, професор, ДВНЗ «Приазовський державний технічний університет», м. Маріуполь, gulakov_s_v@pstu.edu

${ }^{2}$ д-р техн. наук, дочент, ДВНЗ «Приазовський державний технічний університет», м. Маріуполь, VladimirV.Burlaka@gmail.com

мол. наук. співроб., ДВНЗ «Приазовський державний технічний університет», м. Маріуполь, kulyabina-ai@rambler.ru

4 канд. техн. наук, ДВНЗ «Приазовський державний технічний університет», м. Маріуполь, psareva.irina@gmail.com

студент, ДВНЗ «Приазовський державний технічний університет», м. Маріуполь, psareva_masha@mail.ru
} 